\title{
Importance of Occlusion Aspects in the Completion of Orthodontic Treatment
}

\author{
Paula Vanessa Pedron OLTRAMARI ${ }^{1}$ \\ Ana Cláudia de Castro Ferreira CONTI ${ }^{1}$ \\ Ricardo de Lima NAVARRO ${ }^{1,2}$ \\ Márcio Rodrigues de ALMEIDA ${ }^{1}$ \\ Renata Rodrigues de ALMEIDA-PEDRIN ${ }^{1}$ \\ Fernando Pedrin Carvalho FERREIRA ${ }^{1}$ \\ ${ }^{1}$ Department of Orthodontics; ${ }^{2}$ Department of Oral and Maxillofacial Surgery, \\ School of Dentistry, University of Maringá, Maringá, PR, Brazil
}

\begin{abstract}
The purpose of this study was to address the therapeutic goals regarding the static and functional occlusion in the completion of orthodontic treatment. For such purpose, a study population comprising 20 female treated Class II malocclusion subjects with an initial mean age of 11 years underwent a two-phase treatment (orthopedics and orthodontics). The patients were diagnosed in centric relation and were treated according to the six keys for normal occlusion and functional occlusal parameters (centric relation, vertical dimension, lateral and anterior guidances, occlusal contacts and direction of forces applied on the teeth). After removal of fixed mechanics, retainers were installed and maintained for two years. Five years after orthodontic completion, the occlusal stability of the patients was evaluated regarding molar relationship and overjet, measured in dental casts. All subjects maintained the normal molar relationship and correct overjet achieved at the end of treatment, indicating a fair level of occlusal stability. The importance of the criteria of the ideal functional occlusion to ensure a better stability after completion orthodontic treatment will be discussed in detail in this paper. In addition, some clinical situations in which localized adjustments are indicated for occlusal refinement will be described.
\end{abstract}

Key Words: Orthodontics, orthodontic treatment completion, dental occlusion.

\section{INTRODUCTION}

The establishment of the ideal occlusion is the therapeutic goal for orthodontic patients. Angle (1), in 1899, issued the first definition for normal occlusion, which was based on the sagittal relationship of the first permanent molars. He believed that the patient's facial harmony would be achieved with the alignment of all teeth occluding in a normal molar relationship.

Andrews (2), in 1972, complemented this concept while evaluating the natural occlusion of 120 patients. He observed the presence of six common characteristics, which were denominated "six keys to normal occlusion": Inter-arch molar, canine and premolar relationship; mesiodistal crown angulation; buccolingual crown inclination; absence of dental rota- tions; presence of defined proximal contacts and leveling curve of Spee. These six parameters described by Andrews became the aims of the orthodontic treatment. However, these therapeutic goals consist of static characteristics, without considering the functional aspects of the occlusion.

Only in 1976, Roth (3) presented the following functional aspects of the occlusion as being fundamental for completion of the orthodontic cases: 1 . Teeth must present maximum intercuspal (MI) position with the jaw in centric relation (CR); 2 . In centric relation, all posterior teeth must present axial occlusal contacts, and the anterior teeth must maintain a distance of 0.0005 inches between them; 3 . During laterotrusion, the canines must disocclude the posterior teeth (canine guidance); 4. During protrusion, the upper anterior teeth

Correspondence: Dra. Paula Vanessa Pedron Oltramari, Rua Dr. Olímpio de Macedo, 2-50, Vila Universitária, 17012-533 Bauru, SP. Tel/ Fax: +55-14-3234-8869. e-mail: pvoltramari@ig.com.br 
must occlude with the lower anterior teeth and the first premolar or the second premolar (in extraction cases), aiming at disoccluding all posterior teeth (immediate anterior guidance); 5 . No interference must be present on the balancing side.

This paper addresses the importance of the static and functional aspects of the occlusion for the orthodontic therapy. The aim is to establish well defined criteria that might aid the orthodontist obtaining the appropriate completion of the orthodontic treatment.

\section{MATERIAL AND METHODS}

The study population comprised 20 female treated Class II malocclusion subjects with an initial mean age of 11 years. The participants were chosen among patients treated by graduated students of Uningá Dental School and were submitted to a two-phase treatment in order to evaluate their orthodontic stability: the first phase consisted of orthopedic treatment using Bionator for 12 months; in the second part of the treatment, the permanent dentition was completed and all patients were treated using fixed appliances for a mean period of 2 years (19 to 26 months). Patients were diagnosed in centric relation and were treated according to the 6 keys for normal occlusion and functional occlusal parameters (centric relation, vertical dimension, lateral and anterior guidances, occlusal contacts and direction of forces applied on the teeth), which will be further discussed in this paper.

After removal of fixed mechanics, Hawley and canine to canine retainers (4) were installed (in the upper and lower arches, respectively) and maintained for 2 years. Five years after orthodontic completion, the occlusal stability of the patients was evaluated regarding molar relationship and overjet, measured in dental casts. All patients maintained the normal molar relationship and correct overjet achieved at the end of treatment, indicating a fair level of occlusal stability. The above-mentioned functional occlusal parameters used to ensure a better stability after completion orthodontic treatment will be described and discussed in the following section.

\section{DISCUSSION}

Importance of Centric Relation in Orthodontics

The term CR has been used in Dentistry for many years. Despite the great variety of definitions, CR is usually considered to designate the position of the jaw in which the condyles are in a stable orthopedic position $(5,6)$. The mandibular position that relates to occlusion is named maximum intercuspal position. The orthodontist must consider CR and MI positioning during the whole treatment, from the diagnosis to the completion.

The CR position rarely coincides with MI position in the majority of the population, and about $90 \%$ of people have a deviation up to $1.75 \mathrm{~mm}$ between these two positions (7). In the cases in which this deviation alters the sagittal relationship between the upper and lower arches, it seems obvious that the diagnosis and orthodontic planning of treatment must be elaborated based on the patient's examination in CR. When this protocol is neglected, one can obtain an incorrect diagnosis and make an incorrect treatment planning for the real malocclusion. For a clinical example, this error is more common in cases of false Class III and unilateral posterior crossbite. In order to yield the best treatment planning, bilateral jaw manipulation in CR must be performed since the first clinical exam and thereafter at each appointment, so that the orthodontic mechanics is directed to obtain a static and functional ideal occlusion.

As the orthodontic treatment gradually alters the dental contacts, patient's manipulation in CR must often be accomplished in order to maintain the difference between CR and MI within the physiologic limits (up to $1.75 \mathrm{~mm}$ ) during the course of the treatment (7). If a deviation between CR and MI larger than $1.5 \mathrm{~mm}$ is detected in the completion phase, tooth position must be corrected to eliminate the premature contacts causing this discrepancy, or even partial occlusal adjustments shall be done to eliminate these contacts. Given that occlusal adjustment is an irreversible procedure, it must be properly and carefully planned because of the risk of an unnecessary dental reduction (8).

It is also important to emphasize that deviations between CR and MI up to $1.5 \mathrm{~mm}$ must not be overestimated because it is already stated (9) that only discrepancies larger than $4.0 \mathrm{~mm}$ could result in a 2-fold increase of patient's risk to develop signs and symptoms of temporomandibular disorder (TMD).

\section{Maintenance of the Vertical Dimension}

During the fixed orthodontic mechanics, some movements are extrusive and can alter the vertical 
dimension, as well as the orthopedic appliances which act guiding the differential extrusion of the teeth in order to correct the skeletal malocclusions. Extra oral appliances with cervical support used for the Class II treatment due to maxillary excess, which act in the restriction of the anterior development of the maxilla and in the distal movement of the upper molars, may also increase the bite height in patients (10).

However, the alteration of the vertical dimension coincides with the facial vertical development in growing individuals. It indicates that these alterations could usually happen as a consequence of the processes of craniofacial growth. Additionally, the fact of the teeth are tied to the appliances would hinder the dental extrusion. All these alterations attributed to the orthodontic and orthopedic treatment are of small magnitude and therefore are not harmful (11).

\section{Establishment of Lateral Guidance}

Ideally, during the excursive jaw movements, the posterior teeth must not participate of occlusion. This disocclusion must be obtained at the expense of the anterior teeth. Thus, during the jaw protrusive movement, the lower incisal borders slide on the palatal surfaces of the upper incisors, promoting total disocclusion. Likewise, during the lateral movements, the canine must perform the disocclusion. These concepts, known as "mutually protected occlusion", are important to define the occlusal pattern in subjects with complete dentition. Along those lines, the posterior teeth protect the anterior teeth of any contact in the static jaw position and during the excursive movements $(12,13)$.

The establishment of canine guidance is aimed in the orthodontic completion due to several factors: the strategic positioning of the canine in the arch; the favorable root anatomy, presence of a better crownroot proportion; the presence of dense and compact bone around the root, which better tolerates the occlusal forces compared with the medullar bone of the posterior teeth; the sensorial pulse that activates less muscles when the canine teeth are in contact than when posterior teeth contact each other. Therefore, when the jaw is in a right or left laterotrusive movement, the upper and lower canines are the appropriate teeth to contact and to dissipate the horizontal forces, while promoting the disocclusion of the posterior teeth. Another important point is that the achievement of the canine guidance in orthodontics is easier than the group function. It is because mechanically it is much easier to establish the contact in a single tooth than to distribute the contacts simultaneously in all the posterior teeth $(12,13)$.

The group function must be established when the canine teeth do not present an appropriate position to accept the horizontal forces, for example: periodontal problems in the canines, cases of atypical upper lateral incisor agenesis, lower incisor extraction, or in any case that the first premolar replaces the canine. In this last example, the establishment of the lateral guide should be avoided in order to prevent the development of a traumatic occlusion because premolars are not capable of supporting disocclusion.

\section{Establishment of Immediate Anterior Guidance}

When the patient occludes in MI, all posterior teeth must contact, and the anterior teeth must be slightly separated. As soon as the protrusive movement begins, the lower incisors must contact the palatal face of the maxillary incisors, thus allowing the immediate disocclusion of the posterior teeth. For this purpose, some orthodontic parameters must be present, for example, overjet and overbite. If the patient presents an increased overjet (more than $3 \mathrm{~mm}$ ), a longer period is necessary for the anterior teeth to contact, which results in anterior guidance at the expense of the posterior teeth.

Another problem in obtaining the anterior guidance is related to the permanent second molar interferences. When these teeth are not included in the orthodontic treatment and are misaligned in relation to the other teeth, mainly the mandibular second molars, their interferences impede the anterior teeth of accomplishing the anterior guidance.

During completion of the orthodontic treatment, it is extremely important to establish an overjet and overbite of approximately $2 \mathrm{~mm}$, which facilitates the achievement of the anterior guidance. As far as the mandibular second molars are concerned, they must be included in the orthodontic treatment to avoid interferences during the protrusive movement. Additionally, the forces directed out of the long axis of the posterior teeth, associated with the presence of bacterial biofilm, can cause pathologies of occlusal origin, such as excessive wear, dental mobility, gingival recession and cervical lesion $(14,15)$. 


\section{Obtaining Simultaneous Contact Points}

At the end of the orthodontic treatment the interdigitation is executed. In this phase, intermaxillary elastics may be used to promote the contact on the posterior teeth when the patient ocludes in MI. Articular paper should be used to check the occlusal contacts, which must be simultaneous on both sides of the dental arches, and must be present on all the posterior teeth. The larger the number of contacts per tooth, the more balanced the distribution of the occlusal forces. This will allow an occlusal stability, an important factor to reduce the orthodontic relapse. Following these steps, a mutually protected occlusion can be achieved (16).

\section{Direction of Forces Applied on the Teeth}

When a force is applied on a tooth, the fibers of the periodontal ligament support them, and a tension is generated in the alveolus. Pressure is a type of force that the bone tissue does not support. On the other hand, tension stimulates bone formation. Therefore, the periodontal ligament is capable of converting destructive forces (e.g. pressure) into acceptable forces (e.g. tension). Generally, periodontal ligament can be considered as a natural controller of pressure that absorbs the occlusal forces applied on the bone (17).

The direction of the occlusal forces through the tooth long axis is denominated axial load. Axial force is obtained when the contacts occur on the top of the cusps or plane surfaces, perpendicularly to the long axis of the tooth. Also, it may be obtained by the tripodism, in which the cusp should contact the antagonist fossa within three points. In this way, the resulting force is guided by the long axis of the teeth, which promotes the maintenance of the homeostasis in the periodontal structures, with a good bone/tooth relationship.

Short- and long-term success of the orthodontic treatment can be established when all the static and functional objectives of the occlusion are present. One of the criteria to obtain a functional occlusion is to achieve a stable centric relation with all the teeth in the Maxim Intercuspal position (18).

Angle (1) reported the importance of the occlusal factors for the maintenance of the occlusal stability after the completion of orthodontic cases. The establishment of an appropriate occlusion and a perfect interdigitation prevents the dental migration. This isolated factor may not to be enough to maintain the result obtained with the movement, so that the completion based on a functional occlusion improves the stability and may minimize tooth migration.

After the completion phase, important changes in the number and location of the occlusal contacts should not be expected (19), and an occlusion as stable as possible should be reached (18). However, small partial adjustments, considering the patient's habitual intercuspal position, can be performed aiming at the maintenance of the positional stability after the orthodontic treatment. Some clinical situations demand the accomplishment of these partial adjustments, such as surgical cases in adult patients or patients with mutilations; cases with Bolton discrepancy; presence of defective restorations; cases with asymmetric extractions and situations with localized occlusal interferences that might preclude the orthodontic completion.

These localized adjustments may avoid relapses in cases that due to some anatomical or functional reason, a stable occlusion was not possible. Such procedure must be performed with caution and proper planning. Another point to be considered is to explain the reason of the adjustment to the patients (or their guardian). The patient must know that the adjustment is not being made to prevent TMJ problems or headaches, but to improve the occlusal stability and avoid occlusal pathologies, such as the appearance of non-carious cervical lesion, mobility and abrasion.

The static occlusion parameters have been widely considered as goals that must be reached during the orthodontic treatment. However, the orthodontists have neglected the importance of the functional aspects of the occlusion. According to the results obtained, the achievement of the ideal functional occlusion provided a satisfactory stability (maintenance of molar relationship and overjet) after orthodontic treatment. Thus, the success of the orthodontic treatment depends on the establishment of the static and dynamic criteria. This minimizes the orthodontic relapse and prevents the appearance of occlusal pathologies.

\section{RESUMO}

O objetivo deste estudo foi discorrer sobre as metas terapêuticas referentes à oclusão estática e funcional na finalização de casos ortodônticos. Para tanto, 20 jovens do gênero feminino, com idade média inicial de 11 anos, portadoras de má oclusão de Classe II foram submetidas a tratamento em duas fases (ortopédica 
e ortodôntica). As pacientes foram diagnosticadas em relação cêntrica e tratadas de acordo com as seis chaves da oclusão normal e os critérios de oclusão funcional (relação cêntrica, dimensão vertical, guias lateral e anterior, contatos oclusais e direção das forças aplicadas aos dentes). Após a remoção dos aparelhos fixos, aparelhos de contenção foram instalados e mantidos durante dois anos. Cinco anos após a finalização ortodôntica, a estabilidade oclusal foi avaliada em modelos de gesso, considerando-se a relação molar e o trespasse horizontal. Todos os pacientes mantiveram a relação molar normal e o trespasse horizontal obtido ao final do tratamento, evidenciando uma boa estabilidade oclusal. A importância dos critérios da oclusão funcional ideal para garantir uma melhor estabilidade pós-ortodontia será descrita detalhadamente neste artigo, visando guiar o profissional durante a fase de finalização ortodôntica. Ainda, serão relatadas situações clínicas em que pequenos ajustes parciais estão indicados para o refinamento oclusal.

\section{REFERENCES}

1. Angle EH. Classification of malocclusion. Dent Cosmos 1899;41:248-264.

2. Andrews LF. The keys to normal occlusion. Am J Orthod 1972;62:296-309.

3. Roth RH. The maintenance system and occlusal dynamics. Dent Clin North Am 1976;20:761-788.

4. Mamandras AH, Foley TF. Orthodontic retention. J Can Dent Assoc 1996;62:412-414.

5. Dumont TD. Orthodontics. J Am Dent Assoc 2006;137:954955.

6. Rinchuse DJ, Kandasamy S. Centric relation: a historical and contemporary orthodontic perspective. J Am Dent Assoc 2006;137:494-501.

7. Seligman DA, Pullinger AG. Analysis of occlusal variables, dental attrition, and age for distinguishing healthy controls from female patients with intracapsular temporomandibular disorders. J Prosthet Dent 2000;83:76-82.

8. Clark GT, Adler RC. A critical evaluation of occlusal therapy: occlusal adjustment procedures. J Am Dent Assoc 1985;110:743-750.

9. McNamara Jr. JA, Selligman DA, Okeson JP. Occlusion orthodontic treatment and temporomandibular disorders: a review. J Orofac Pain 1995;9:73-90.

10. Wyatt W. Preventing adverse effects on the temporomandibular joint through orthodontic treatment. Am J Orthod Dentofacial Orthop 1987;91:493-499.

11. Rivera-Morales WC, Goldman BM. Are speech-based techniques for determination of occlusal vertical dimension reliable? Compend Contin Educ Dent 1997;18:1214-1215.

12. Williams EH, Lundquist DO. Anterior guidance: its effect on the electromyographic activity of the temporal and masseter muscles. J Prosthet Dent 1983;49:816-825.

13. Willianson EH. Occlusion and TMJ disfunction. J Clin Orthod 1981;15:333-342.

14. Burgett FG. Trauma from occlusion. Periodontal concerns. Dental Clin North Am 1995;39:301-311.

15. Manns A, Miralles R, Valdivia J, Bull R. Influence of variation in anteroposterior occlusion contacts on electromyographic activity. J Prosthet Dent 1989;61:617-623.

16. Standlee JP, Caputo AA, Ralph JP. Stress transfer to the mandible during anterior guidance and group function at centric movements. J Prosthet Dent 1979;34:35-45.

17. Glickman I. Inflammation and trauma from occlusion. J Periodontol 1963;34:5-15.

18. Haydar B, Ciger S, Saatçi P. Occlusal contact changes after the active phase of orthodontic treatment. Am J Orthod Dentofac Orthop 1992;102:22-28.

19. Egermark I, Carlsson GE, Magnusson T. A prospective longterm study of signs and symptoms of temporomandibular disorders in patients who received orthodontic treatment in childhood. Angle Orthod 2005;75:645-650.

Accepted November 20, 2006 